\begin{abstract}
Iranica
Abstracta Iranica Revue bibliographique pour le domaine irano-aryen

Volume 32-33 | 2013

Comptes rendus des publications de 2009-2010

\section{Mark Slobin. Central Asian Film Music as a Subcultural System}

Ariane Zevaco

\title{
OpenEdition
}

1 Journals

Édition électronique

URL : http://journals.openedition.org/abstractairanica/40166

DOI : 10.4000/abstractairanica.40166

ISSN : 1961-960X

Éditeur :

CNRS (UMR 7528 Mondes iraniens et indiens), Éditions de l'IFRI

\section{Édition imprimée}

Date de publication : 1 décembre 2013

ISSN : 0240-8910

\section{Référence électronique}

Ariane Zevaco, "Mark Slobin. Central Asian Film Music as a Subcultural System », Abstracta Iranica [En ligne], Volume 32-33 | 2013, document 473, mis en ligne le 01 juillet 2016, consulté le 29 septembre 2020. URL : http://journals.openedition.org/abstractairanica/40166 ; DOI : https://doi.org/10.4000/ abstractairanica.40166

Ce document a été généré automatiquement le 29 septembre 2020.

Tous droits réservés 


\title{
Mark Slobin. Central Asian Film Music as a Subcultural System
}

\author{
Ariane Zevaco
}

\section{RÉFÉRENCE}

Mark Slobin. «Central Asian Film Music as a Subcultural System ». Ethnomusicology Forum, vol. 18, $\mathrm{n}^{\circ} 1,2009$, p. 153-164.

1 Quelles sont les stratégies employées par les réalisateurs, à travers la construction de la musique d'un film, pour refléter une ou des inscription(s) identitaire(s) soviétique, nationale, locale et/ou régionale ? C'est la question posée et étudiée par Mark Slobin dans cet article. La qualification de la musique de film comme "subcultural system » renvoie à celle de "subcultural cinema ", que Slobin a définit dans son récent livre (Mark Slobin, (ed.), Global Soundtracks: world of Film Music, Middletown, CT, Wesleyan University Press, 2008.) comme " a body of work produced by minority filmmakers within a multicultural society" (p. 153). Cette définition réfère à un travail de domestication, de reformulation et parfois d'opposition à l'approche dominante (ici, celle de la politique culturelle soviétique) du rôle et de la nature de la musique de film.

2 Slobin revient ainsi sur les traditions locales de réalisation : il parle de « regional film music» (p. 154) pour désigner les musiques des films d'Asie centrale, en regard du « supercultural system » construit par l'Etat soviétique. Il tente de clarifier la relation entre l'affirmation régionale par rapport au système culturel de l'URSS, et la mission d'affirmation nationale inhérente au projet soviétique dans les républiques socialistes. C'est la recherche de cet équilibre qui fait selon lui l'originalité du traitement musical dans les films centrasiatiques.

3 A partir de différents exemples de films produits en Asie centrale entre les années 1960 et 1990, Mark Slobin détaille les différentes stratégies adoptées dans l'utilisation de la musique dans les films, comme 'source' (produite par les personnages du film) ou 'score' (jouée par des musiciens invisibles). Les multiples combinaisons entre musique 
régionale, nationale, soviétique, mais aussi l'usage de musiques traditionnelles réarrangées par des orchestres symphoniques, témoignent d'autant de tactiques de réalisations pour affirmer une identité locale, ou non, et jouer sur des niveaux de compréhension différents. L'A. analyse ainsi différents choix esthétiques, qui constituent autant de symboles politiques et culturels, et revient également sur les notions de tradition (souvent traitée à travers une musique qualifiée d'ethnographique) et d'authenticité. Slobin analyse ainsi, de manière détaillée, un pan de la production artistique souvent peu étudié en Asie centrale, celui de la musique de film, et la façon dont les réalisateurs ont pu en jouer pour affirmer des identités culturelles, sociales et politiques. Cela lui permet également de faire le lien entre études cinématographiques et musicales; une connexion amplement justifiée par la diversité des activités des musiciens à l'époque soviétique (et souvent encore pratiquée en Asie centrale contemporaine), entre lieux de théâtre, de cinéma et de musique.

\section{AUTEURS}

ARIANE ZEVACO

Paris 